\title{
Salinity Profile Estimation in the Pacific Ocean from Satellite Surface Salinity Observations
}

\author{
SENLIANG BAO \\ Institute of Meteorology and Oceanography, National University of Defense Technology, Nanjing, and State Key \\ Laboratory of Satellite Ocean Environment Dynamics, Second Institute of Oceanography, \\ State Oceanic Administration, Hangzhou, China \\ REN ZHANG \\ Institute of Meteorology and Oceanography, National University of Defense Technology, Nanjing, China \\ HUIZAN WANG \\ Institute of Meteorology and Oceanography, National University of Defense Technology, Nanjing, and State Key \\ Laboratory of Satellite Ocean Environment Dynamics, Second Institute of Oceanography, \\ State Oceanic Administration, Hangzhou, China \\ HENGQIAN YAN AND YANG YU \\ Institute of Meteorology and Oceanography, National University of Defense Technology, Nanjing, China \\ JIAN CHEN \\ Beijing Institute of Applied Meteorology, Beijing, China
}

(Manuscript received 2 January 2018, in final form 27 October 2018)

\begin{abstract}
A nonlinear empirical method, called the generalized regression neural network with the fruit fly optimization algorithm (FOAGRNN), is proposed to estimate subsurface salinity profiles from sea surface parameters in the Pacific Ocean. The purpose is to evaluate the ability of the FOAGRNN methodology and satellite salinity data to reconstruct salinity profiles. Compared with linear methodology, the estimated salinity profiles from the FOAGRNN method are in better agreement with the measured profiles at the halocline. Sensitivity studies of the FOAGRNN estimation model shows that, when applied to various types of sea surface parameters, latitude is the most significant variable in estimating salinity profiles in the tropical Pacific Ocean (correlation coefficient $R$ greater than 0.9). In comparison, sea surface temperature (SST) and height (SSH) have minimal effects on the model. Based on FOAGRNN modeling, Pacific Ocean three-dimensional salinity fields are estimated for the year 2014 from remote sensing sea surface salinity (SSS) data. The performance of the satellite-based salinity field results and possible sources of error associated with the estimation methodology are briefly discussed. These results suggest a potential new approach for salinity profile estimation derived from sea surface data. In addition, the potential utilization of satellite SSS data is discussed.
\end{abstract}

\section{Introduction}

Salinity plays a significant role in the ocean circulation and the Earth global hydrological cycle. Salinity, along with ocean temperature, is required to compute ocean density and provides key information about water mass formation, mixed layer depth, barrier layer depth, and

Corresponding author: H. Wang, wanghuizan@126.com geostrophic circulation (de Boyer Montégut et al. 2007; Helber et al. 2010; Qin et al. 2015; Rao and Sivakumar 2003; Wang and Zhang 2012). Further, sea surface salinity is a key variable reflecting changes in the global freshwater budget, and its spatial and temporal distributions provide useful information for understanding the hydrological cycle, including evaporation, precipitation, river runoff, and melting ice. Meanwhile, salinity is also known to be relevant in large-scale atmosphere-ocean 
climate signals, such as El Niño-Southern Oscillation (ENSO) (Ballabrera-Poy et al. 2002; Qu and Yu 2014; Singh and Delcroix 2011; Zhu et al. 2014). The scientific importance of measuring and analyzing salinity is becoming increasingly recognized.

Unlike temperature, in situ salinity measurements have been undersampled over the oceans. With the deployment of global ocean observing systems, such as Argo floats, voluntary observing ships, and moored platforms, the number of in situ salinity measurements has been improved over the last few years. The Argo program has now realized a deployment of more than 3000 units of vertical salinity profiles from subsurface (5-10 m) to 2000-m depth every two weeks with an average spatial resolution of $300 \mathrm{~km}$. However, sampling remains irregular and inhomogeneous, and available salinity data are far from being adequate to characterize spatial and temporal variability of salinity at mesoscale scales. On the other hand, with the development of remote sensing technology, an increasing amount of satellite data is available for study. For example, the remote sensing salinity satellites, Soil Moisture and Ocean Salinity (SMOS) and Aquarius/ Satélite de Aplicaciones Cientificas-D (SAC-D), launched in 2009 and 2011, respectively, were the pioneers to collect data on ocean salinity from space (Kerr et al. 2010; Le Vine et al. 2010). Satellite remote sensing observations provide extensive near-real-time data for the global ocean sea surface salinity every 3 (SMOS) or 7 (Aquarius) days with a spatial resolution of roughly $40 \mathrm{~km}$ for SMOS and $100 \mathrm{~km}$ for Aquarius.

However, as satellite observations are confined to the surface, the subsurface observations are still scarce in most parts of the ocean. A method that projects these high-resolution surface data into the ocean interior is crucial for better understanding of the interior ocean and better initialization of a numerical model for reliable forecasts (Agarwal et al. 2007). Consequently, several studies have estimated vertical profiles from sea surface measurements by investigating the relationship between sea surface data and vertical structures within oceans (Chen et al. 2017). These methodologies include linear regression (Fox et al. 2002b; Nardelli and Santoleri 2004; Carnes et al. 1994; Fox et al. 2002a; Guinehut et al. 2012; Nardelli and Santoleri 2005), empirical orthogonal function (EOF) reconstruction (Maes et al. 2000; Nardelli and Santoleri 2005; Wang et al. 2012), coupled pattern reconstruction (CPR) (Nardelli and Santoleri 2004), and intelligent methods (Agarwal et al. 2007; Gueye et al. 2014; Wu et al. 2012; Krasnopolsky et al. 2006; Krasnopolsky 2007, 2013)

However, the reconstruction of the vertical profiles from surface data often results in anomalous results. Specifically, data at different depths of the profiles might correspond to a single surface measurement. Moreover, the problem is complex in that the vertical profile data from different depths are much greater in quantity than the associated surface data. Such reconstruction models often face problems of nonlinearity, complexity, and incomplete knowledge of the mechanisms that govern the formation of these profiles (Gueye et al. 2014). Therefore, the results of inverse models remain inadequate in the ocean areas with complex vertical stratification and rich small-scale phenomena, such as vertical mixing.

Furthermore, several studies have shown that sea surface salinity (SSS) data provide important information related to reconstruction of three-dimensional salinity fields (Agarwal et al. 2007; Ballabrera-Poy et al. 2009; Nardelli and Santoleri 2005). This emphasizes the potential applications of satellite salinity observations, when combined with in situ temperature-salinity $(T-S)$ profiles, for estimation of vertical salinity profiles. However, the performance of SSS observations in constructing vertical salinity profiles has rarely been evaluated using data from satellites. Previous research was based on SSS data from drifting/moored buoys or Argo floats. Therefore, it is imperative to utilize SMOS/Aquarius satellite data on the reconstruction of vertical salinity profiles. In this paper, the generalized regression neural network based on the fruit fly optimization algorithm (FOAGRNN) is proposed to improve the vertical salinity profile reconstruction method. Additionally, satellite sea surface salinity data are used to construct three-dimensional salinity fields based on the FOAGRNN as a means to assess the efficacy of satellite salinity data in reconstruction of 3D salinity fields.

This paper is organized as follows. Data are presented in section 2 , methods are presented in section 3 , the performance of FOAGRNN in estimating salinity profiles is evaluated in section 4 , the assessment of the performance of satellite salinity data on the reconstruction of 3D salinity fields is provided in section 5, and results and discussion are presented in section 6 .

\section{Data}

Three sources of ocean observations are used in this study: in situ data, satellite altimeter sea level anomalies (SLAs), and satellite SSSs. Each is described below. The World Ocean Atlas 2013 (WOA13) climatology, used as climatology monthly means, is also described.

\section{a. In situ data}

The in situ profiles are obtained from the EN.4.1.1 dataset provided by the Met Office Hadley Centre. The dataset covers the period from 1900 to the present and is based on ocean temperature and salinity profiles data obtained from the World Ocean Database 2009 
TABLE 1. The number of profiles being used for training and validation in the tropical Pacific Ocean and the Kuroshio Extension region.

\begin{tabular}{lcr}
\hline \hline & Training & Testing \\
\hline Tropical Pacific Ocean & 159787 & 28337 \\
Kuroshio Extension region & 28536 & 3157 \\
\hline
\end{tabular}

(WOD09), the Global Temperature and Salinity Profile Programme (GTSPP), Argo, and Arctic Synoptic BasinWide Observations (ASBO) collections (Good et al. 2013). Profiles extending to a depth of $1200 \mathrm{~m}$ and starting no deeper than $10 \mathrm{~m}$ were selected. The profiles were interpolated into the same 28 vertical levels extending from the surface to $1200 \mathrm{~m}$. The vertical step is $10 \mathrm{~m}$ for the first 12 levels (5-125 m), $25 \mathrm{~m}$ for the next 7 levels $(125-300 \mathrm{~m})$, $50 \mathrm{~m}$ for the following 4 levels $(300-500 \mathrm{~m}), 100 \mathrm{~m}$ for the next 3 levels $(500-800 \mathrm{~m})$, and $200 \mathrm{~m}$ for the remaining 2 levels $(800-1200 \mathrm{~m})$. These profiles were then used as training data for the period 2004-2013 to compute the statistics that relate the surface field data to the subsurface field data, to test data to retrieve $S$, and for independent data validation (for 2014). Table 1 shows the number of profiles being used for training and testing.

The EN.4.1.1 dataset also provided the monthly objective analyses, which are computed on a $1^{\circ} \times 1^{\circ}$ grid by objective analysis method using in situ profiles after quality control. The monthly gridded fields from 2014 are used for comparison with the retrieved $S$ fields from satellite sea surface salinity data.

\section{b. Gridded maps of altimeter SLAs}

The altimeter SLA data were provided by SSALTO/ Data Unification and Altimeter Combination System (DUACS) and distributed by Archiving, Validation, and Interpretation of Satellite Oceanographic Data (AVISO) with support from CNES (http://www.aviso. oceanobs.com/duacs/). These data consist of gridded SLA obtained from an optimized combination of four available satellite altimeters and are used primarily for global sea level change studies. The SLA data over the period from 2003 to 2014 , with daily and $0.25^{\circ} \times$ $0.25^{\circ}$ resolutions, are used in this paper.

\section{c. Gridded maps of sea surface salinity observation}

Satellite SSS data have been primarily obtained from three different sea surface salinity gridded datasets from multiple institutions, including Centre Aval de Traitement des Données SMOS (CATDS) CATDS Expertise Center (CEC) Laboratoire d'Océanographie et du ClimatExpérimentations et Analyse Numérique (LOCEAN), version 2013 [SMOS CATDS CEC LOCEAN_v2013 (SMOS LOCEAN)], data provided by CATDS in France; SMOS Barcelona Expert Center (BEC) Level 4
(SMOS BEC) data provided by the BEC in Spain; and Aquarius V3.0 combined active-passive (CAP) L3 (Aquarius CAP) data provided by the NASA Jet Propulsion Laboratory (JPL) in the United States.

SMOS LOCEAN data are obtained from ESA L2 v5 data using simple averaging following thorough filtering of inconsistencies with the SSS data. They are distributed in netCDF format (www.catds.fr/Products/Availableproducts-from-CPDC). SMOS BEC data are computed from L2 salinity data of the ESA 2012 and 2013 reprocessing campaigns and distributed in netCDF format (http://cp34-bec.cmima.csic.es). The data are extracted with a singularity analysis-based fusion technique. The analysis-based fusion technique is a spatial filter that can be used to increase the spatial resolution of the fused maps and to reduce noise (Umbert et al. 2014). Two products of the SMOS satellite are averaged by month and gridded with a horizontal resolution of $0.25^{\circ} \times 0.25^{\circ}$.

Aquarius CAP data are processed monthly on a $1^{\circ} \times 1^{\circ}$ grid by the Ocean Biology Processing Group (OBPG) of the NASA Goddard Space Flight Center (GSFC) and distributed by the Physical Oceanography Distributfed Active Archive Center (PO.DAAC) of the NASA Jet Propulsion Laboratory (JPL) in Hierarchical Data Format (HDF5) and netCDF format, respectively (ftp://podaac-ftp. jpl.nasa.gov/allData/aquarius/). This analysis utilizes the CAP algorithm (Yueh and Chaubell 2012) to simultaneously retrieve the salinity and wind data without using the NCEP winds for corrections and corrects any salinity deviation dependent on SST data.

\section{d. WOA13 climatology data}

The climate data used in this study are from the WOA13, which are provided by the National Oceanographic Data Center (NODC)(http://apdrc.soest. hawaii.edu/data/data.php), using the historical observation profiles of mechanical bathythermography (MBT), ship-deployed conductivity-temperature-depth (CTD) packages, expendable bathythermographs (XBT), digital bathythermograph (DBT), and other instruments, for the period from 1955 to 2012, to obtain the standard layer temperature and salinity field with a spatial resolution of $0.25^{\circ} \times 0.25^{\circ}$, including monthly, seasonal, and annual averages. The average monthly gridded fields are used in this study.

\section{Method}

\section{a. The multiple linear regression method}

The linear regression method is widely used to derive vertical profiles. The subsurface $S$ can be estimated using multiple linear regression: 


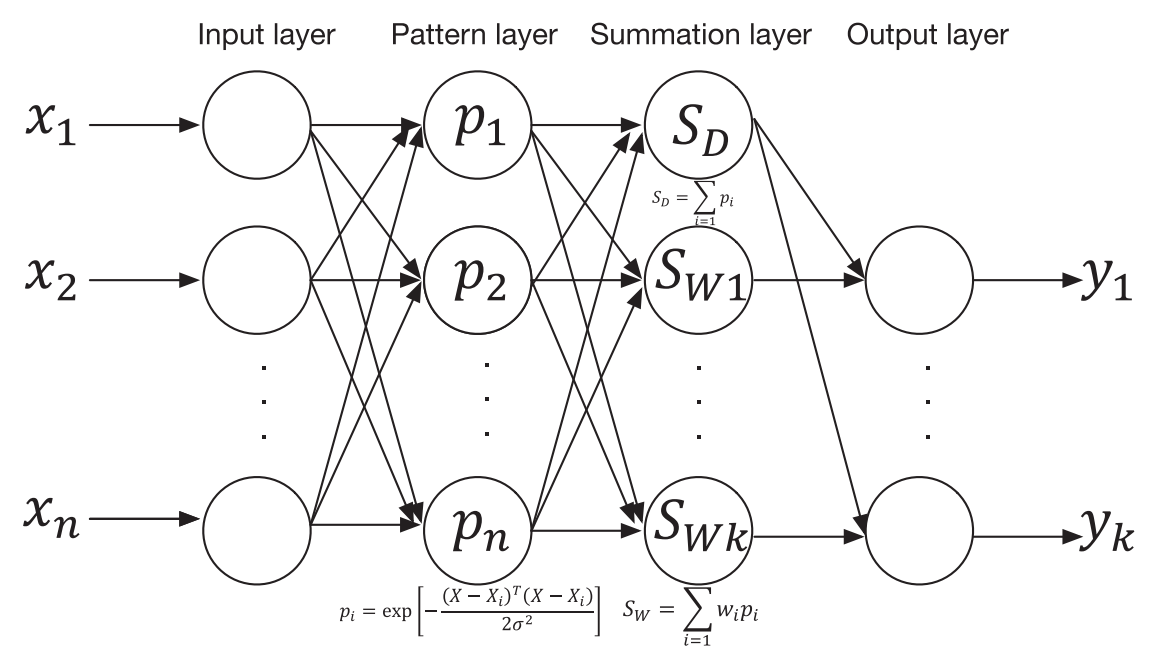

FIG. 1. Structure of the GRNN.

$$
\begin{aligned}
S(x, y, z, t)= & \lambda(x, y, z, t) \times \operatorname{SLA}^{\prime}(x, y, t)+\theta(x, y, z, t) \\
& \times \operatorname{SSS}^{\prime}(x, y, t)+S_{\text {clim }}(x, y, z, t),
\end{aligned}
$$

where SLA ${ }^{\prime}$ and SSS $^{\prime}$ denote SLA and SSS anomalies with respect to monthly climatology $S_{\text {clim }}$; and $\lambda$ and $\theta$ represent regression coefficients of SLA and SSS onto $S$, respectively. These parameters vary with depth, location, and time (for clarity, only depth will be shown from now on) and can be expressed as covariance between the variables:

$$
\begin{aligned}
& \lambda(z)=\frac{\left\langle\mathrm{SSS}^{\prime}, \mathrm{SSS}^{\prime}\right\rangle \times\left\langle\mathrm{SLA}^{\prime}, S(z)^{\prime}\right\rangle-\left\langle\mathrm{SLA}^{\prime}, \mathrm{SSS}^{\prime}\right\rangle \times\left\langle\mathrm{SSS}^{\prime}, S^{\prime}(z)\right\rangle}{\left\langle\mathrm{SLA}^{\prime}, \mathrm{SLA}^{\prime}\right\rangle \times\left\langle\mathrm{SSS}^{\prime}, \mathrm{SSS}^{\prime}\right\rangle-\left\langle\mathrm{SLA}^{\prime}, \mathrm{SSS}^{\prime}\right\rangle^{2}}, \\
& \theta(z)=\frac{\left\langle\mathrm{SLA}^{\prime}, \mathrm{SLA}^{\prime}\right\rangle \times\left\langle\mathrm{SSS}^{\prime}, S(z)^{\prime}\right\rangle-\left\langle\mathrm{SLA}^{\prime}, \mathrm{SSS}^{\prime}\right\rangle \times\left\langle\mathrm{SLA}^{\prime}, S^{\prime}(z)\right\rangle}{\left\langle\mathrm{SLA}^{\prime}, \mathrm{SLA}^{\prime}\right\rangle \times\left\langle\mathrm{SSS}^{\prime}, \mathrm{SSS}^{\prime}\right\rangle-\left\langle\mathrm{SLA}^{\prime}, \mathrm{SSS}^{\prime}\right\rangle^{2}} .
\end{aligned}
$$

The regression coefficients $(\lambda$ and $\theta)$ are calculated for each point on a $1^{\circ} \times 1^{\circ}$ grid using all of the historical (2004-13) in situ observations in a radius of influence of $5^{\circ}$ latitude and $10^{\circ}-25^{\circ}$ longitude to achieve a minimum of 500 profiles (Guinehut et al. 2012).

\section{b. FOAGRNN}

\section{1) GRNN}

In 1991, Donald F. Specht put forward a generalized regression neural network (GRNN), which is a variety of the radial basis function (RBF) network (Specht 1991). Characterized by strong nonlinear mapping abilities, a flexible network structure, a high fault tolerance, and robustness, the GRNN is suitable for solving nonlinear problems, even with a small number of samples (Gao et al. 2015; Lin 2013; Lixi et al. 2014; Verma et al. 2015; Zhou et al. 2016). Similar with the structure of the RBF network, the GRNN consists of four layers, including input, pattern, summation, and output layers (Fig. 1).

The theoretical basis of the GRNN is the nonlinear regression analysis of dependent variables $y$ relative to the independent variable $x$, assuming that the joint probability density function of random variable $x$ and random variable $y$ is $f(X, y)$. The regression of $y$ is shown in Eq. (4):

$$
\hat{Y}(X)=E(Y \mid X)=\frac{\int_{-\infty}^{+\infty} Y f(X, y) d y}{\int_{-\infty}^{+\infty} f(X, y) d y},
$$

where $\hat{Y}(X)$ is the prediction output of $Y$ in the condition input $X$.

The estimation of the density function $\hat{f}(X, Y)$ is based on the sample dataset $\left\{x_{i}, y_{i}\right\}_{i=1}^{n}$ with the Parzen nonparametric estimation method, as shown in Eq. (5): 


$$
\begin{aligned}
\hat{f}(X, Y)= & \frac{1}{n(2 \pi)^{(p+1) / 2} \sigma^{p+1}} \sum_{i=1}^{n} \exp \left[-\frac{\left(X-X_{i}\right)^{\mathrm{T}}\left(X-X_{i}\right)}{2 \sigma^{2}}\right] \\
& \times \exp \left[-\frac{\left(Y-Y_{i}\right)^{2}}{2 \sigma^{2}}\right]
\end{aligned}
$$

where $X_{i}$ and $Y_{i}$ are sample observation values of random variable $x$ and $y$, respectively; $n$ is the sample size; $p$ is the dimension of random variable $x$; and $\sigma$ is the width coefficient of the Gauss function, herein called the smoothing parameter.

If $f(X, y)$ is replaced with $\hat{f}(X, Y)$ in the equation, the network output $\hat{Y}(X)$ can be expressed in Eq. (6):

$$
\hat{Y}(X)=\frac{\sum_{i=1}^{n} Y_{i} \exp \left[-\frac{\left(X-X_{i}\right)^{\mathrm{T}}\left(X-X_{i}\right)}{2 \sigma^{2}}\right]}{\sum_{i=1}^{n} \exp \left[-\frac{\left(X-X_{i}\right)^{\mathrm{T}}\left(X-X_{i}\right)}{2 \sigma^{2}}\right]}
$$

The output $\hat{Y}(X)$ is the weighted average of all sample observation values $Y_{i}$. The weight factor of each $Y_{i}$ is weighted exponentially according to its Euclidean distance from $X$.

Therefore, the GRNN model has only one parameter $\sigma$ (also called the spread parameter in MATLAB) that needs to be determined from Eq. (6). The smoothing parameter determines the GRNN prediction accuracy and generalization ability, which plays an important role in the GRNN. Many researchers have selected the smoothing parameter; however, based on prior knowledge and personal experience, it contributes to errors in the regression ( $\mathrm{Li}$ et al. 2013). Therefore, we chose to design an automatic and efficient method to optimize the parameter. This study uses the fruit fly optimization algorithm (FOA) to automatically determine the smoothing parameter value of the GRNN model.

\section{2) THE GRNN BASED ON THE FOA (FOAGRNN)}

The fruit fly optimization algorithm is a new probabilistic method intended to find a global optimum based on the fruit fly's foraging behaviors. Fruit flies are superior to other species in terms of olfactory and visual senses. They can successfully pick up various odors floating in the air and fly to that location. They also find the gathering locations of other fruit flies and fly in that direction (Pan 2012). Meanwhile, the FOA uses a two-dimensional search in both $x$ axis and $y$ axis; it is powerful enough to achieve global optimization. Because of its merits, many researchers have used the FOA to optimize the parameters of artificial neural network models (Li et al. 2013; Lin 2013).

According to the foraging characteristics of fruit flies, the FOA can be divided into several steps. Step 1, the initial positions of fruit fly swarm are generated randomly. Step 2, each fruit fly is randomly assigned a direction and distance for its movement to look for food. Step 3, calculate the distance of the fly to origin Dist and the smell concentration judgment value $S$, which is the inverse of the Dist. The smell concentration Smell is calculated by substituting $S$ into the smell concentration judgment function (also called fitness function). Step 4, the individual fruit fly with the maximal smell concentration is determined. The maximal smell concentration value and coordinate are kept. Then, the fruit fly travels to the location with the maximal smell concentration. The iterative optimization is entered to repeat steps 2-4. Finally, when the smell concentration is not greater than the previous iteration smell concentration or when the number of iterations reaches the maximum number of iterations, the loop stops. More details about the FOA are available online (http://www. oitecshop.byethost16.com/FOA.html).

In this paper the FOA is used to select the appropriate smoothing parameter value of the GRNN model in order to improve the prediction accuracy and generalization ability of the model. The flowchart of the FOA for the parameter selection of the GRNN model (FOAGRNN) is shown in Fig. 2. The variable $S$ is input into the GRNN model as the smoothing parameter. Then, the smell concentration Smell $(i)$ (also called the cost function value) is calculated by employing the root-mean-square error (RMSE) between the GRNN model output and the actual value.

The flowchart of applying the FOAGRNN method to salinity estimation at each layer is shown in Fig. 3. The details are described as follows.

Step 1. The process of sample data

In this paper the sample data were selected from the profiles in the Pacific Ocean between 2004 and 2014. The sample data were divided into training data and testing data. The training sample data spanned 2004 to 2013, and 2014 profiles were used as testing data to retrieve $S$. The sea surface temperature (SST), SSS, SLA, longitude (LON), and latitude (LAT) were selected as the input data of the FOAGRNN model. The SST and SSS were from the uppermost layer of the profiles. The SLA was derived from satellite altimetry SLA data, and the LON and LAT are the position of profiles at that point. The input data were normalized within the range of $0-1$ prior to the training process. The output variable is the $S$ of each layer. 


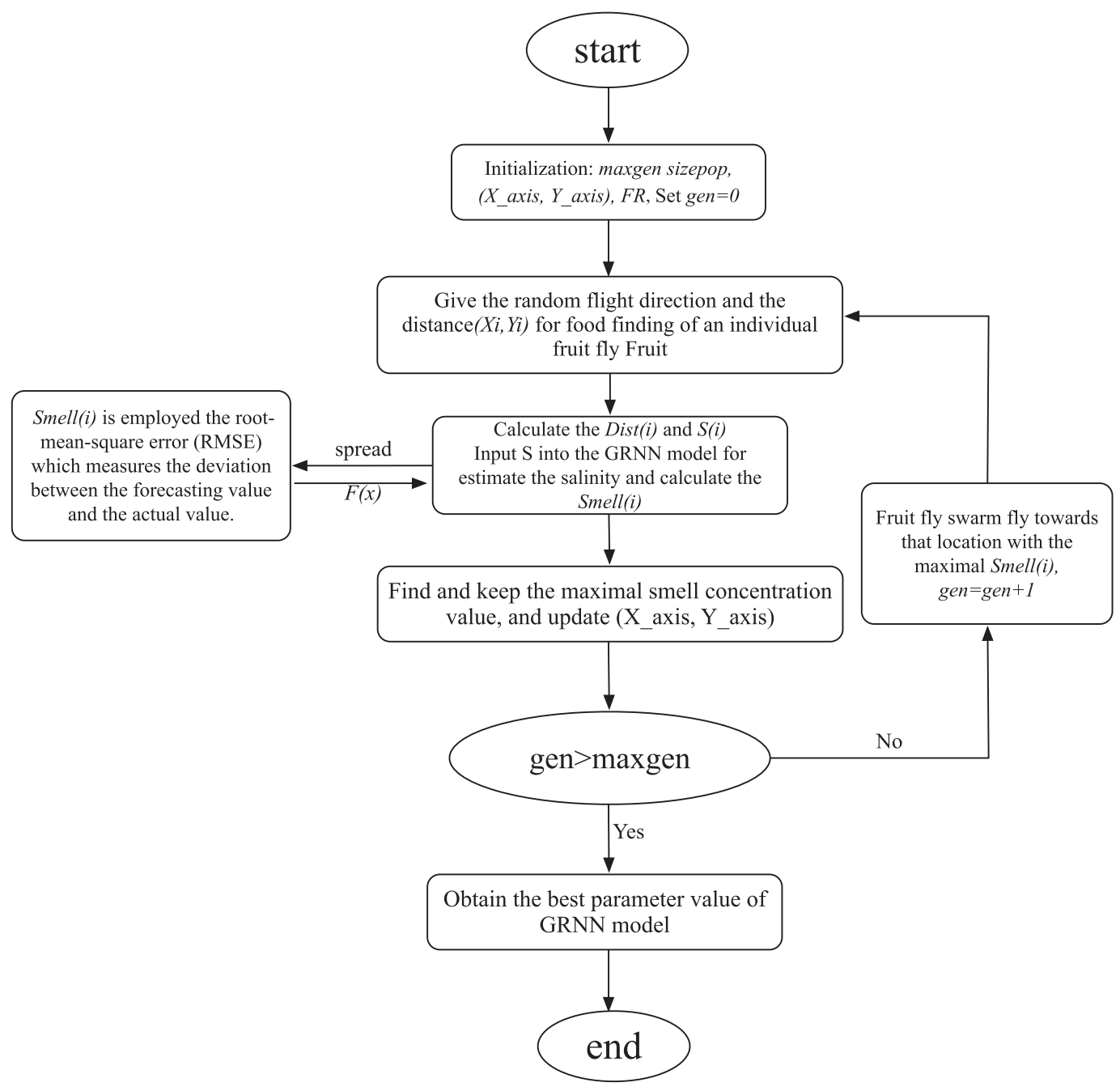

FIG. 2. Flowchart of the FOAGRNN model.

Step 2. Training of the GRNN model

In the FOAGRNN model, the smoothing parameter value of the GRNN model can be dynamically adjusted by the FOA. The initial smoothing parameter value of the GRNN model was set up to be in the range of [0.001, 1]. There are five neurons in the input layer and one output neuron. Then, set the initial parameters of FOA and calculate the distance of every fly to the origin and the variable called smell concentration judgment value, which was put into the smoothing parameter of GRNN. After that, the training data (profiles from 2004 to 2013) were input into GRNN to obtain the network output. With the actual value, Smell $(i)$ is calculated by employing the RMSE between the estimation of the salinity at each layer and the in situ measurement value: The smaller the RMSE, the better (through maximizing 1/RMSE). After the iterative process, the smoothing parameter value can be adjusted to the optimal value by taking the final value of best smell concentration so that the RMSE can be adjusted to minimum. For example, the results of 100 times of iteration and evolution at the depth of $200 \mathrm{~m}$ in the Kuroshio Extension region show that the convergence can be seen in generation 25 with a coordinate of $(8.2585$, $7.0724)$, and the RMSE value and the spread parameter value are 0.01122 and 0.092 , respectively.

Step 3. Estimation of the salinity values of each layer Putting in the input data from 2014, the salinity values of each layer in the Pacific Ocean can be estimated based on the FOAGRNN model.

In summary, the main goal of the FOAGRNN is generating the optimal smoothing value of the generalized regression neural network through the fruit fly optimization algorithm, based on in situ $T-S$ profiles data 


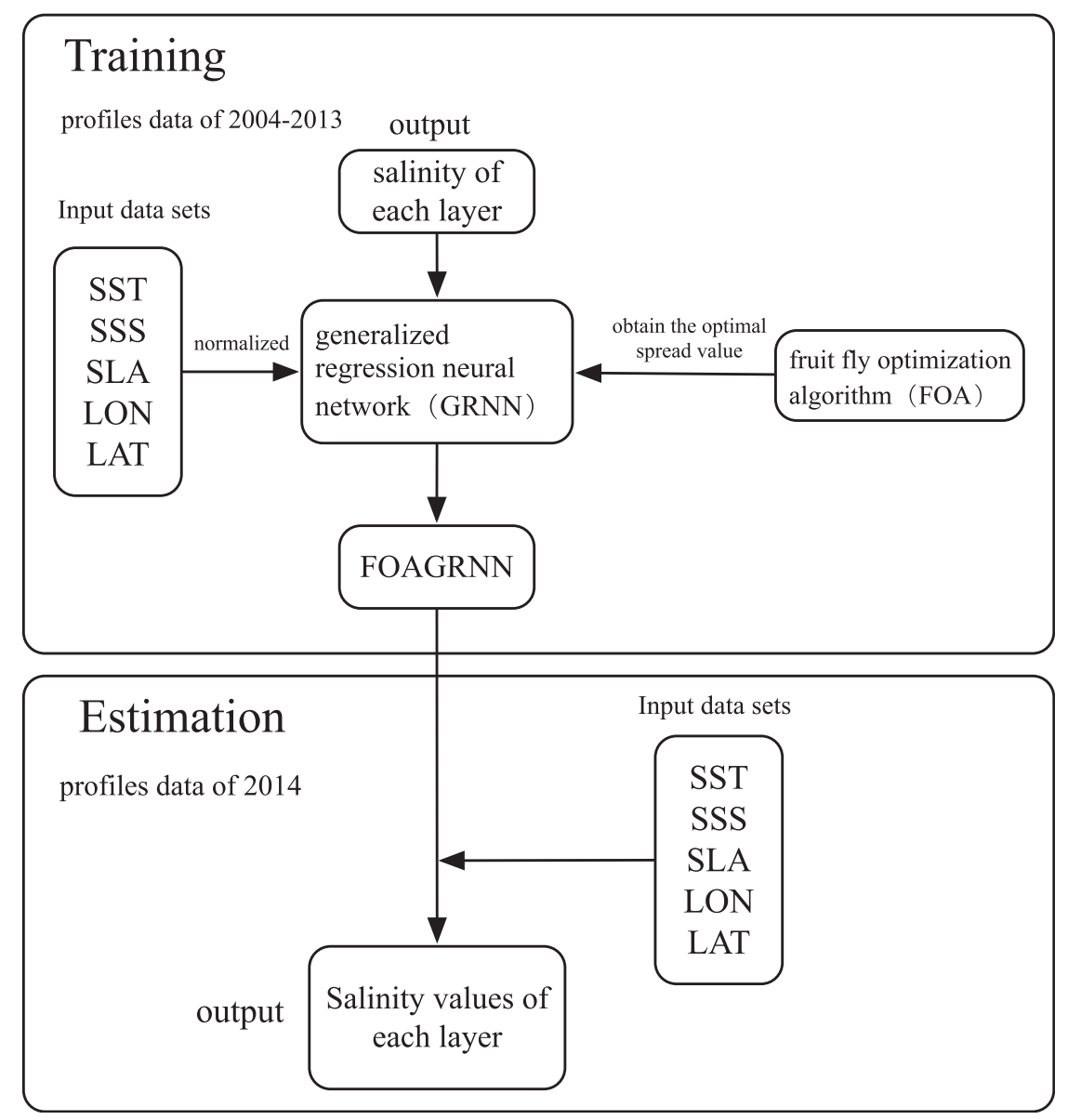

FIG. 3. Flowchart of salinity estimation using the FOAGRNN.

from 2004 to 2013, thereby establishing the vertical salinity profile reconstruction model. The profile data from 2014 are then used for testing the model.

\section{The performance of the FOAGRNN in estimating salinity profiles}

\section{a. Comparison with the linear method}

To evaluate the performance of the FOAGRNN method, the multiple linear regression and FOAGRNN methods are used to retrieve salinity profiles for the tropical Pacific Ocean and the Kuroshio Extension region during 2014. Then, the RMSE of estimated profiles from the two methods against in situ observations was calculated (Fig. 4). Besides, the monthly gridded WOA data were interpolated to the 2014 in situ profile data, and the RMSE of the WOA data was calculated by comparing the WOA salinity profiles with the corresponding in situ profile data (the blue profile). In general, the RMSEs of the estimated profiles using the two methods are less than that of the climatological profiles in nearly all levels. The change of the RMSE with depth from the two methods is close. Below approximately $100 \mathrm{~m}$, the effect of the FOAGRNN is slightly better than that of the linear method, especially with regard to the Kuroshio Extension region.

Figure 5 shows the distribution of the RMSE of the estimated salinity profiles in the tropical Pacific Ocean using the two methods. As shown in Fig. 5, the performance of both methods is good across most of tropical Pacific Ocean region. The RMSE of the estimated profiles and the observation profiles is generally less than 0.1 . However, the RMSE of the linear method is rather high in the red boxes marked A and B. Five observations are selected randomly in the A region and the estimated salinity profiles using the two methods are shown in Fig. 6. The estimated salinity profiles using the linear method have great error with in situ profiles at the depth of the halocline. Compared with linear method, the variation of salinity profiles with depth using the FOAGRNN method is in good agreement with the measured profiles. As shown in the figure of the distribution of equatorial 

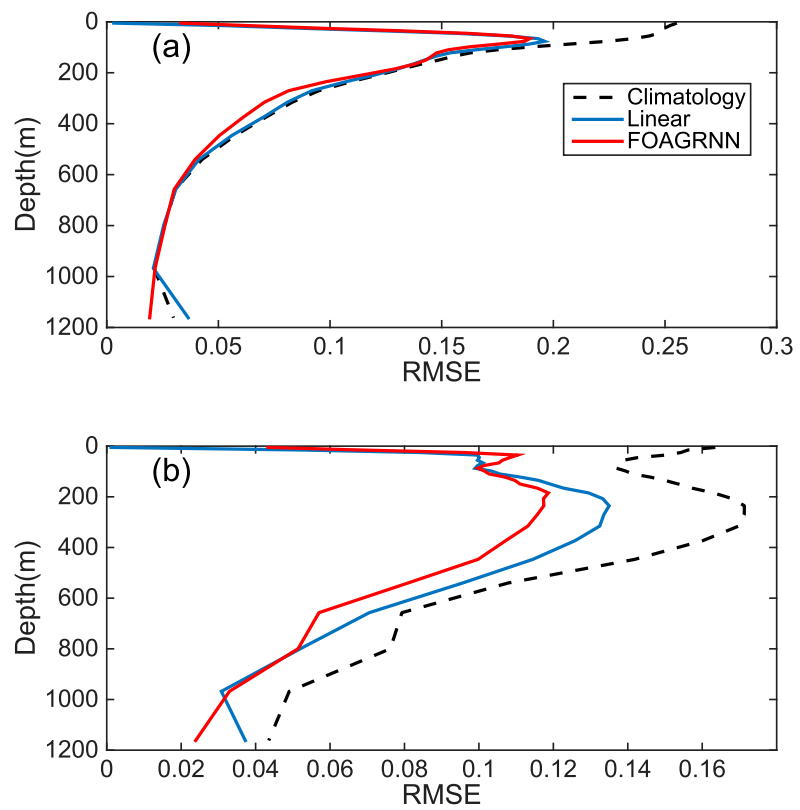

FIG. 4. Mean RMSE of the two reconstruction methods as a function of depth of the (a) tropical Pacific Ocean and (b) Kuroshio Extension region (black dashed line: linear; red solid line: FOAGRNN). Besides, the monthly gridded WOA data were interpolated to the 2014 in situ profile data, and the RMSE of the $W O A$ data was calculated by comparing the WOA salinity with the corresponding in situ profile data (the blue climatology line).

flow (Fig. 7), there are two divergence zones located in the areas between the North Equatorial Current and the Equatorial Countercurrent and the South Equatorial Current across the equator. Low-salinity waters build up at the top layer and there is upwelling resulting from the divergence of surface flow, leading to a large vertical gradient at the halocline at $0-100 \mathrm{~m}$ compared with the total tropical Pacific Ocean (Fig. 6f), that affects the reconstruction results. Table 2 gives the mean RMSE of the estimated profiles in the A and B zones using the two methods. The performance of the FOAGRNN is better than the linear method in the divergence zones. The mean RMSE of the estimated profiles using the FOAGRNN ( $\mathrm{RMSE}=0.168 \mathrm{psu}$ ) is lower than that of the linear method $(\mathrm{RMSE}=0.217$ psu) in the A zone, which shows the superiority of the FOAGRNN methodology as applied to salinity profiles with a large vertical gradient at the halocline.

To further evaluate the performance of different methods in constructing salinity profiles, comparisons of the estimated profiles and the in situ profiles at various latitudes are made in the Kuroshio Extension region (Fig. 8). Overall, the performance of the FOAGRNN method is better than that of the linear method (Table 3), especially at the depth of $100-400 \mathrm{~m}$ in the $32.5^{\circ}-35^{\circ} \mathrm{N}$ portion of the Kuroshio Extension region (Fig. 8b).
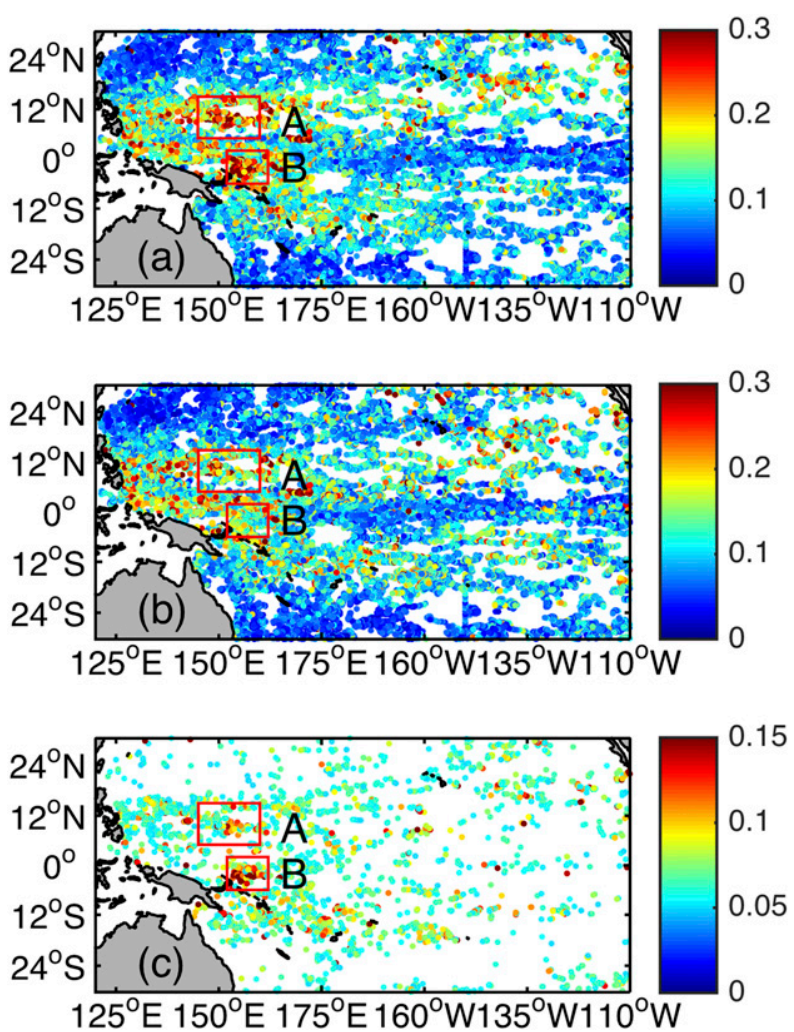

FIG. 5. Distribution of the RMSE of reconstructed salinity profiles in the tropical Pacific Ocean using the two methods: (a) linear method and (b) the FOAGRNN method. (c) Bias of the two methods: Bias $=$ RMSE_linear - RMSE_FOAGRNN, $\Delta$ RMSE $>$ 0.05 is marked.

A tenfold cross validation of the tropical Pacific Ocean data over the period of 2004-13 was performed to further evaluate the ability of the FOAGRNN reconstruction model. By dividing the training data from 2004 to 2013 into 10 yearly subsets, one year of data was withheld at a time as validation data and the remaining nine subsets of data were used as training sets for constructing the FOAGRNN. The salinity profiles were derived by the FOAGRNN, and the results were compared with the validation dataset. Then, the average correlation coefficient and the mean root-mean-square error of the model were taken as the indexes upon which to base the evaluation of the FOAGRNN method. As shown in Table 4, the root-mean-square error and the

TABLE 2. The mean RMSE of the estimated profiles in the divergence zone with the two methods.

\begin{tabular}{lcc}
\hline \multicolumn{1}{c}{ RMSE } & A & B \\
\hline Linear & 0.217 & 0.191 \\
FOAGRNN & 0.168 & 0.152 \\
\hline
\end{tabular}



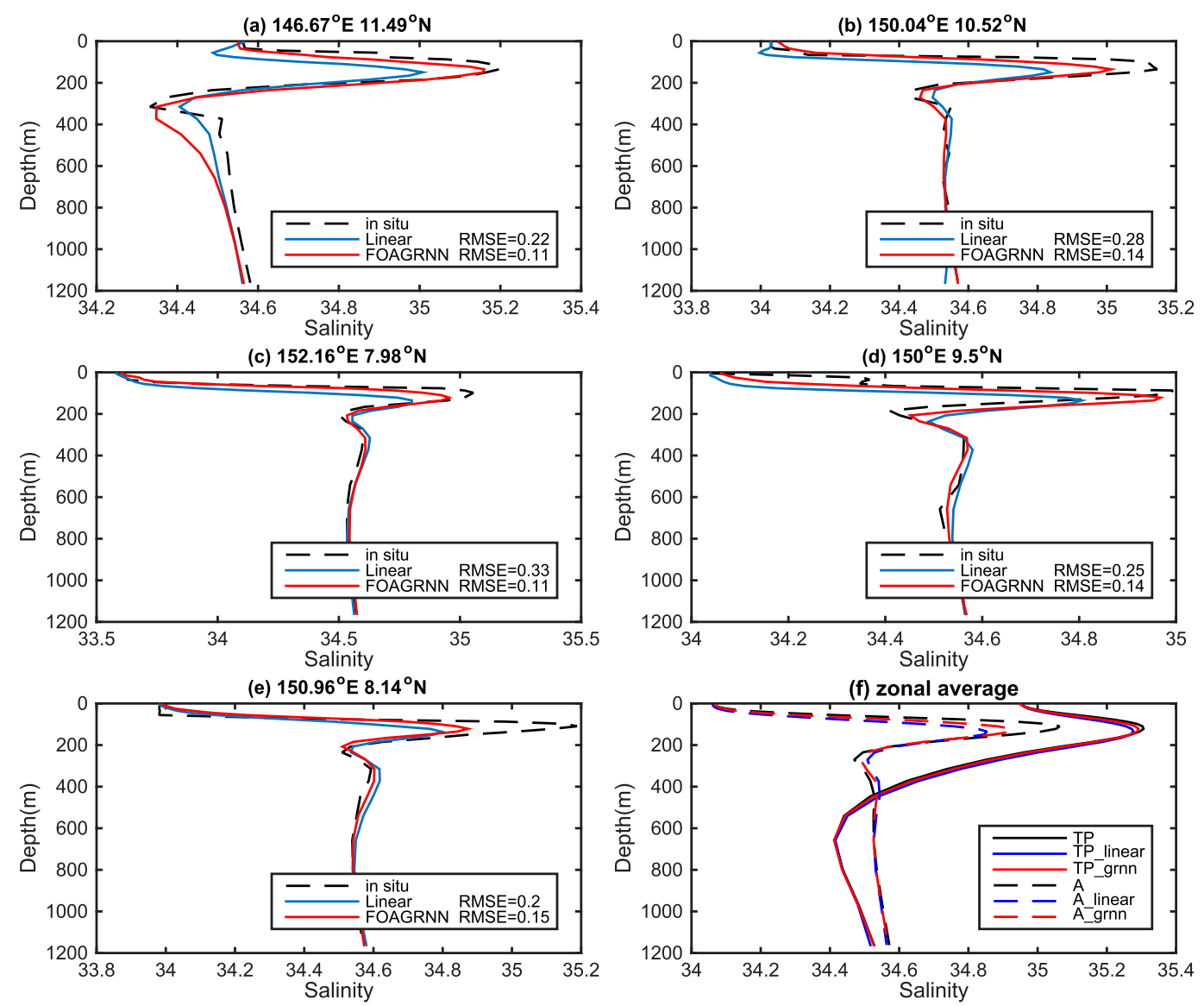

FIG. 6. (a)-(e) Estimated salinity profiles using the two methods in selected observations and (f) zonal average profiles in the A zone and the tropical Pacific Ocean. RMSE of estimated profiles using the two methods are labeled.

average correlation coefficient of the tenfold crossvalidation results are relatively consistent, with an average root-mean-square error of approximately 0.08 and an average correlation coefficient of 0.98 . The rootmean-square error and the mean correlation coefficient between the estimated salinity and the measured salinity data in cross validation, as a function of depth, are shown in Fig. 9. The RMSE and the correlation coefficient $R$ are basically inversely related over depth, especially in the upper ocean. The RMSE increases with the depth and reaches a maximum of 0.13 at the halocline, and then it decreases slowly with only minor changes in the deep layer. The correlation coefficient $R$ begins to decrease down to 0.96 and then increases at deeper levels. The difference lies in that $R$ is reduced in the deep layer. In summary, the results of the cross validation in the tropical Pacific Ocean have small fluctuation (or variance), the RMSE of the estimated results and the measured data are small (about 0.081), and $R$ is large (about 0.98 ), reflecting the stability and effectiveness of the FOAGRNN reconstruction method.

\section{b. Sensitivity of different sea surface parameters in the FOAGRNN estimation}

To test the ability of different sea surface data to describe salinity changes across the interior of the

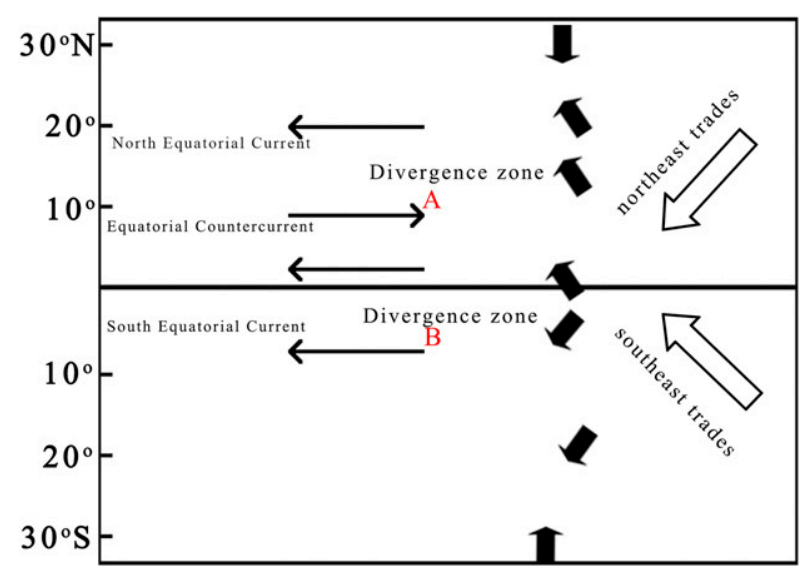

FIG. 7. Distribution of equatorial flow. 

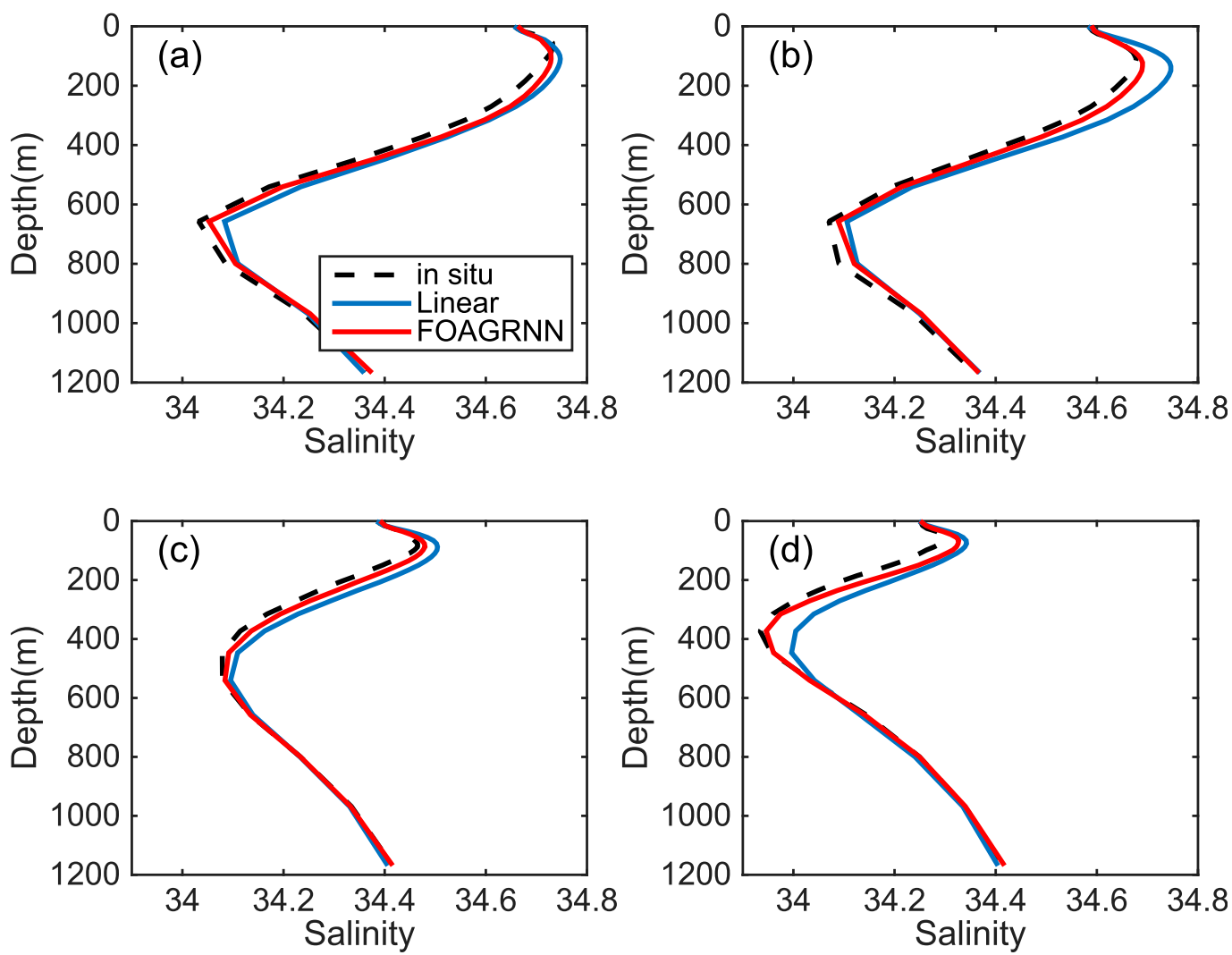

FIG. 8. Observed salinity (black dashed curves), and estimated salinity profiles with different methods at various latitudes (solid lines). (a) $30^{\circ}-32.5^{\circ} \mathrm{N}$, (b) $32.5^{\circ}-35^{\circ} \mathrm{N}$, (c) $35^{\circ}-37.5^{\circ} \mathrm{N}$, (d) $37.5^{\circ}-40^{\circ} \mathrm{N}$ (black dashed line: in situ data; red solid line: FOAGRNN; blue solid line: linear).

ocean, we adopt different combinations of sea surface parameters as sea surface inputs to estimate the salinity profiles. The variation of the root-mean-square error and the correlation coefficient with depth in the tropical Pacific Ocean and Kuroshio Extension region under different sea surface inputs are shown in Figs. 10 and 11 , respectively.

The RMSE of the model (SST SSH LON LAT) is large in the upper layer of the tropical Pacific Ocean and it gradually decreases from 0.25 to 0.2 over the depth range from 0 to $100 \mathrm{~m}$, while the RMSE of other models ranges from 0 to 0.18 . There are almost no differences between the models below $100 \mathrm{~m}$. The large

TABLE 3. Comparisons of the estimated profiles and the in situ profiles at various latitudes.

\begin{tabular}{cccccc}
\hline \hline & \multicolumn{2}{c}{ RMSE } & & \multicolumn{2}{c}{ Correlation coefficient } \\
\cline { 2 - 3 } \cline { 6 - 6 } & Linear & FOAGRNN & & Linear & FOAGRNN \\
\hline a & 0.035 & 0.022 & & 0.994 & 0.997 \\
b & 0.056 & 0.019 & & 0.990 & 0.998 \\
c & 0.047 & 0.020 & & 0.976 & 0.995 \\
d & 0.060 & 0.034 & & 0.958 & 0.986 \\
\hline
\end{tabular}

error of the model (SST SSH LON LAT) without SSS in the upper ocean reveals that when SSS data are added to the model, they mainly improve the effect of salinity reconstruction in the upper ocean but have little influence on the deeper layer; this finding is consistent with previous results (Ballabrera-Poy et al. 2009; Hansen and Thacker 1999).

By comparing the model (SSS SSH LON LAT) and model (SST SSS SSH LON LAT), the surface parameter SST has been found not to provide a noticeable improvement in the reconstruction of salinity profiles. For SSH, the reconstruction effect of the calculated salinity profiles has not been significantly improved in the tropical Pacific Ocean. However, the use of the

TABLE 4. Cross-validation results in the tropical Pacific Ocean.

\begin{tabular}{lccccc}
\hline \hline & 1 & 2 & 3 & 4 & 5 \\
\hline RMSE & 0.082 & 0.082 & 0.081 & 0.082 & 0.082 \\
Correlation coefficient & 0.980 & 0.983 & 0.9804 & 0.980 & 0.980 \\
\hline & 6 & 7 & 8 & 9 & 10 \\
\hline RMSE & 0.081 & 0.082 & 0.082 & 0.081 & 0.083 \\
Correlation coefficient & 0.981 & 0.980 & 0.9798 & 0.980 & 0.979 \\
\hline
\end{tabular}




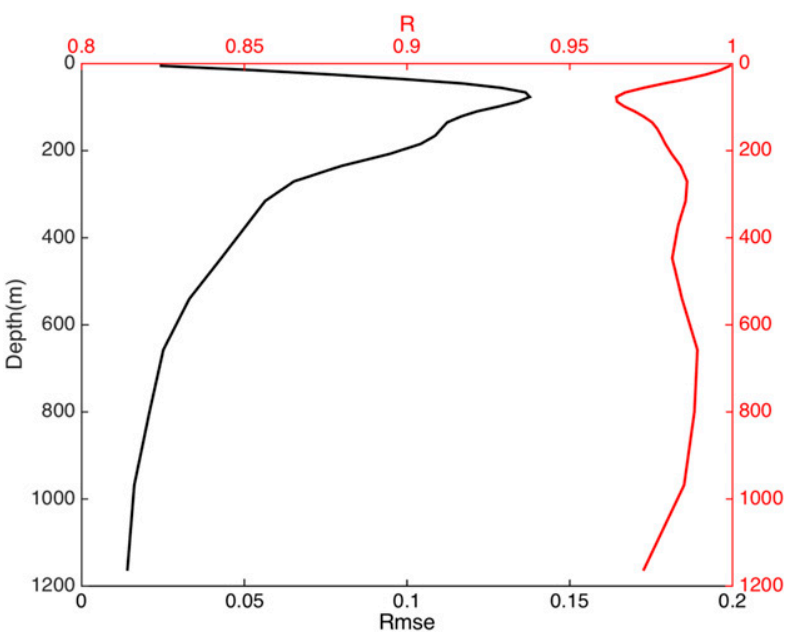

FIG. 9. The RMSE and mean correlation coefficient of estimated salinity compared with the measured salinity data in cross validation as a function of depth (black solid line: RMSE; red solid line: $R$ ).

parameter SSH slightly improved the reconstruction effect in the midocean layer (approximately 200$600 \mathrm{~m}$ ) in the Kuroshio Extension region. The difference is primarily caused by the variation of the sea surface height anomaly distribution between the two locations. The variation of sea surface height in the tropical Pacific Ocean is minimal, while the SSH in the Kuroshio Extension varies greatly (Fig. 12). Overall, the SSH plays only a small part in salinity reconstructions.

The differences between the model (SST SSS SSH LON LAT) and the model (SST SSS SSH) illustrate that the greatest improvement is obtained when latitude and longitude are added to the model. The RMSE of the model demonstrates only minimal changes from depths of 0 to $100 \mathrm{~m}$, but the root-meansquare error of the estimated profiles is greatly reduced, and the correlation coefficient is substantially increased below $100 \mathrm{~m}$. Especially in the tropical Pacific Ocean, the minimum correlation coefficient of the estimated profiles in each layer is more than 0.9 , which obviously improves the reconstruction result of the salinity profile, reflecting the importance of geographic information in the reconstruction of salinity profiles. The corresponding weight coefficients of the training network are adjusted through the addition of geographical parameters, which improves the reconstruction of salinity profiles. The model (SST SSS SSH LAT) and the model (SST SSS SSH LON) are compared with the model (SST SSS SSH). With the inclusion of the latitude data in the model, the maximum root-mean-square error is reduced from 0.42 to 0.19. However, with the addition of longitude data,
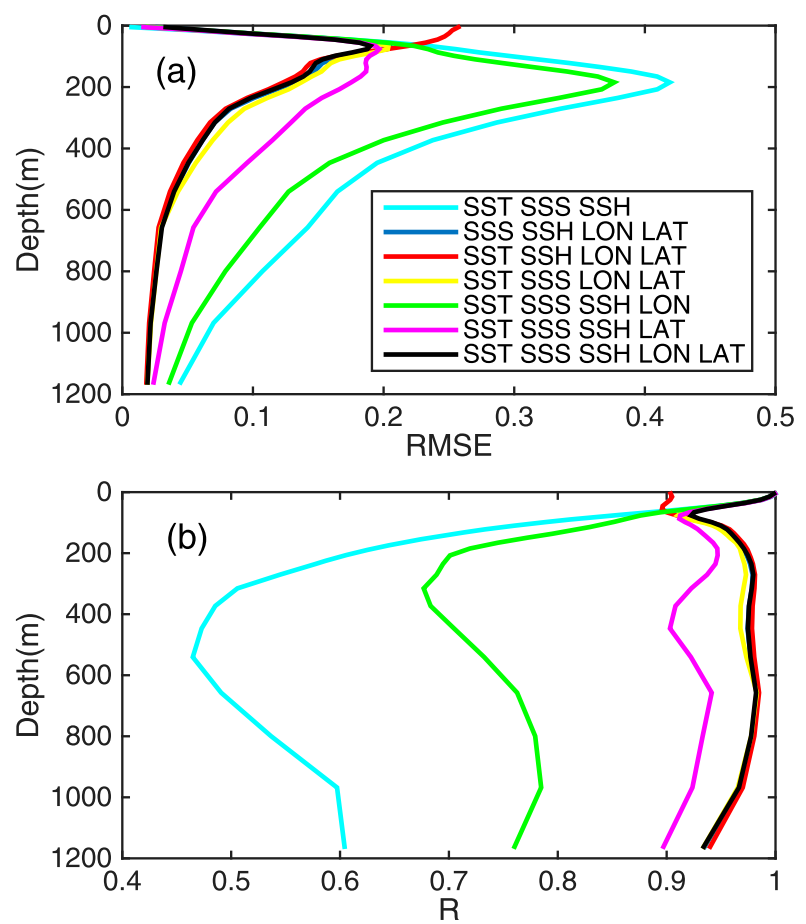

FIG. 10. The RMSE and correlation coefficient of models with different sea surface inputs as a function of depth in the tropical Pacific Ocean. The different inputs of the model are (SST SSS SSH), (SSS SSH LON LAT), (SST SSH LON LAT), (SST SSS LON LAT), (SST SSS SSH LON), (SST SSS SSH LAT), and (SST SSS SSH LON LAT): (a) RMSE and (b) $R$.

the RMSE maximum is only slightly reduced. This shows that latitude data can better improve the reconstruction effect of the salinity profile compared with longitude data.

Based on these results, we can better understand the difference between the RMSE of the estimated profiles using various models to display the role of each piece of sea surface information. For example, Fig. 13 displays the influence of SST (Fig. 13a), SSS (Fig. 13b), SSH (Fig. 13c), LAT (Fig. 13d), and LON (Fig. 13e).

From Figs. 13a and 13c, when SST and SSH are used as the sea surface inputs to retrieve salinity profiles, with few exceptions, the improved accuracy of most profiles is small. In these cases, the difference in the RMSE is generally less than 0.05 . However, when SSS is included in the sea surface input, the RMSE of most retrieved profiles is reduced more than 0.2 (Fig. 13b). By comparison of inputs containing versus lacking latitude information, it can be found that there is a significant improvement in the profiles in the north tropical Pacific Ocean and the area of the eastern coast of Australia (Fig. 13d), thereby reflecting the importance of latitude information. 

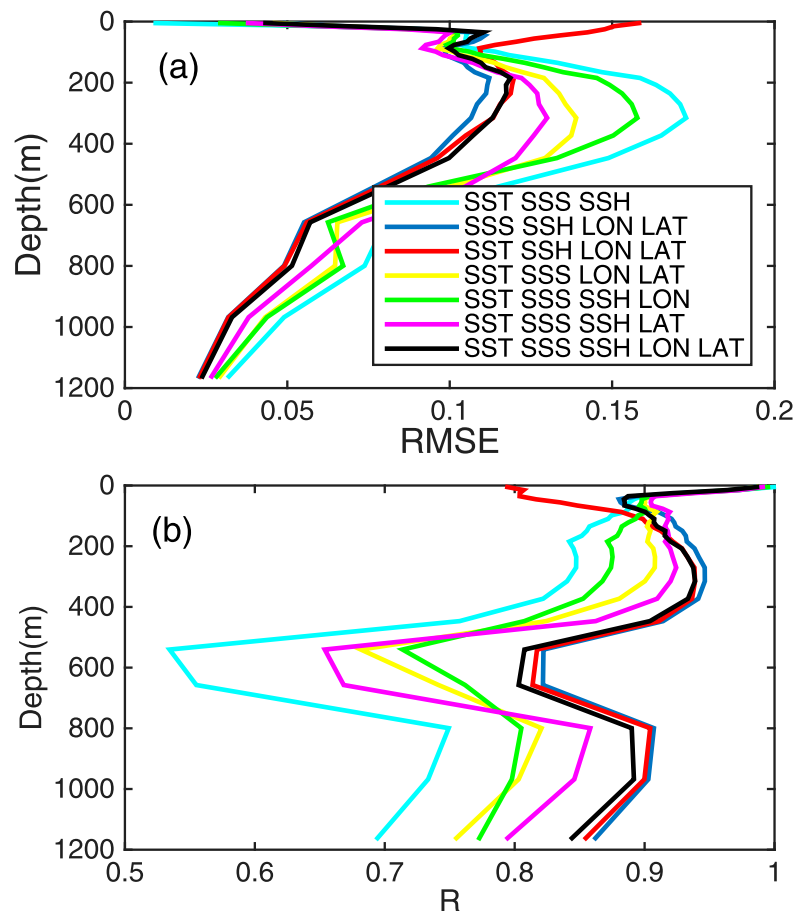

FIG. 11. The RMSE and correlation coefficient of models with different sea surface inputs as a function of depth in the Kuroshio Extension region. The different inputs of the model are (SST SSS SSH), (SSS SSH LON LAT), (SST SSH LON LAT), (SST SSS LON LAT), (SST SSS SSH LON), (SST SSS SSH LAT), and (SST SSS SSH LON LAT): (a) RMSE and (b) $R$.

\section{The performance of satellite salinity data on the reconstruction of 3D salinity fields}

In this section all satellite SSS products are interpolated into the same spatial resolutions as the EN.4.1.1 objective analyses $\left(1^{\circ} \times 1^{\circ}\right)$. Then, the interpolated monthly satellite sea surface salinity data in 2014 are used as SSS input data for the FOAGRNN reconstruction model to estimate the salinity fields in the tropical Pacific Ocean. The estimated three-dimensional salinity fields are calculated and compared to the EN.4.1.1 objective analyses.

The January 2014 salinity field is selected to reflect the basic condition of retrieving satellite salinity data because the comparisons are similar for all other months. The in situ salinity data and the estimated salinity fields for the Pacific Ocean at varying depths are shown in Fig. 14. According to Fig. 14, the salinity fields from satellite data in each layer show good agreement with the measured salinity field in terms of the characteristics of large-scale salinity. The striking features are the western Pacific salinity front on the sea surface, a high $-S$ area located in the southeastern tropical Pacific Ocean, and a low- $S$ area located in the northeast at the
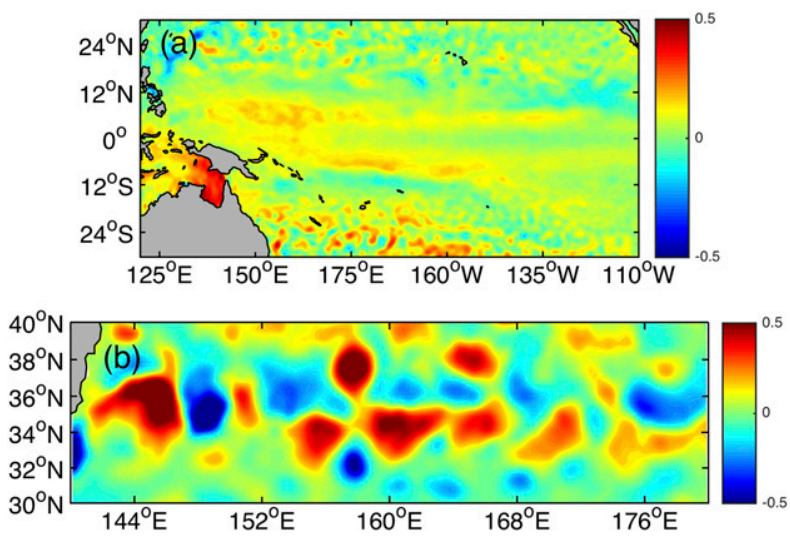

FIG. 12. Anomalous distribution of sea level in 2014 for the (a) tropical Pacific Ocean and (b) Kuroshio Extension region.

depth of $100 \mathrm{~m}$. These results indicate that the estimated salinity fields derived from satellite data with the FOAGRNN coincide with the basic characteristics of the measured salinity fields in each layer.

Compared to the performance of the SMOS satellite, the performance of Aquarius CAP is superior and some detailed features are captured, such as a low-salinity center located north of the equator at a depth of $100 \mathrm{~m}$ and a tongue structure extending from northeast to southwest at a depth of $500 \mathrm{~m}$ in the tropical Pacific Ocean, while the estimated salinity fields derived from SMOS satellite data do not characterize these spatial distribution features.

Figure 15 shows the RMSE between the estimated salinity fields and the measured gridded salinity fields (the EN.4.1.1 objective analyses) in 2014, whose SSS input data are from the uppermost layer of the gridded EN.4.1.1 objective analyses and the monthly satellite sea surface salinity products. Because of the error of the satellite salinity data, the RMSE of the salinity profiles estimated by satellite SSS products are larger than that by the empirically measured data, especially in the upper ocean. The performance of Aquarius CAP data is the best among the three satellite salinity datasets, followed by that of SMOS BEC. In the upper ocean, the Aquarius CAP data have improved salinity estimation compared with the climatology data, while SMOS products have failed to provide any improvement. It could be related to the error of satellite products in the tropical Pacific Ocean. The RMSE between Aquarius CAP and in situ salinity data in 2014 is smallest $(\mathrm{RMSE}=0.24 \mathrm{psu})$ compared with the SMOS products (Fig. 16). It shows that a smaller error in the satellite salinity input results in more accurate estimated salinity profiles.

For the salinity profile estimation from the surface parameters, the main error could be attributable to the error of the surface parameters or the reconstruction 

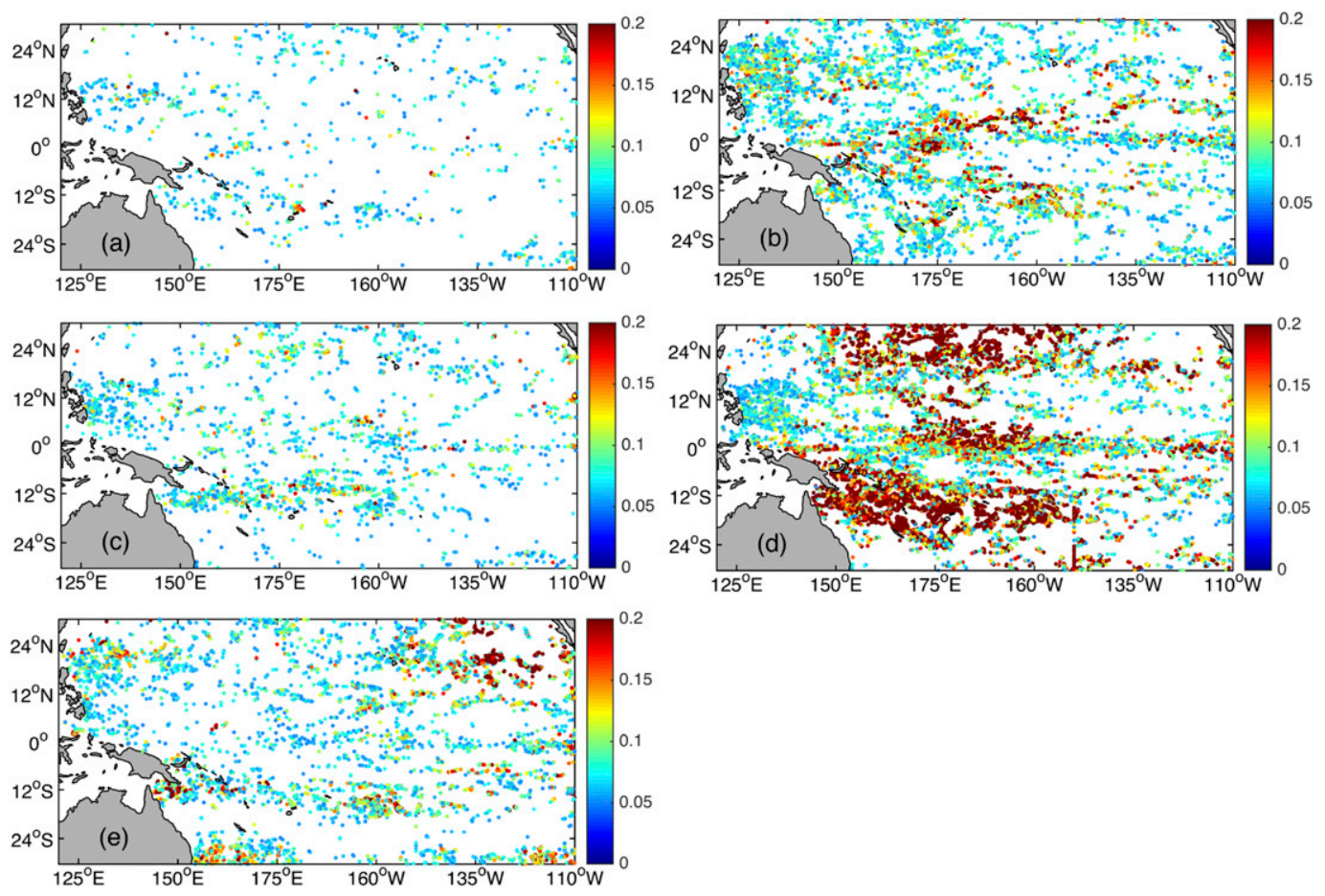

FIG. 13. Difference distribution of the RMSE of salinity profiles retrieved from different sea surface information inputs in the tropical Pacific Ocean: (a) RMSE (SSS SSH LON LAT) - RMSE (SST SSS SSH LON LAT), (b) RMSE (SST SSH LON LAT) RMSE (SST SSS SSH LON LAT), (c) RMSE (SST SSS LON LAT) - RMSE (SST SSS SSH LON LAT), (d) RMSE (SST SSS SSH LON) - RMSE (SST SSS SSH LON LAT), and (e) RMSE (SST SSS SSH LAT) - RMSE (SST SSS SSH LON LAT); $\Delta$ RMSE $>0.05$ is marked.

method. We regard the error of estimated salinity profiles using in situ measurements as being caused by the reconstruction method. The difference between the error of the retrieved salinity profiles using satellite salinity data and the error caused by the reconstruction method is regarded as the error induced from inaccurate SSS values. As is shown in Fig. 17, the profile of the reconstruction method error is roughly symmetrical to that of SSS-induced error. The SSS-induced error is more important in the mixed layer. As depth increases, the error caused by the inaccuracy of SSS decreases rapidly, which indicates that the SSS information projects onto only the ocean mixed layer. The reconstruction method error increases gradually and reaches the maximum at the halocline. At this time, the error introduced by the reconstruction method is the primary source of errors. The two types of errors are very small as applied to the deep ocean.

\section{Discussion and conclusions}

In this paper a statistical model (FOAGRNN) was proposed to reconstruct salinity profiles in the Pacific Ocean using climatological in situ profiles and satellite
SSS data. The goal of this work was to assess the ability of the FOAGRNN model to estimate salinity profiles and to evaluate the performance of satellite salinity data on the reconstruction of 3D salinity fields.

There are mainly two error sources in the salinity profile estimation. One error source is the reconstruction method error. The FOAGRNN method is a statistical approach based on the relationship between the sea surface data and vertical structures within oceans. Because of the different dynamic processes, such as downwelling and upwelling, the relationship between sea surface signals and subsurface salinity may vary widely. In this paper profiles from the entire tropical Pacific Ocean were used to train the FOAGRNN, and the empirical relationship of the whole areas was extracted. In the equatorial west Pacific, there is upwelling resulting from the divergence of surface flow, leading to large vertical gradient at the halocline at $0-100 \mathrm{~m}$ compared with the total tropical Pacific Ocean (Fig. 6f). This is an outstanding feature in the equatorial west Pacific, which leads to the error of $S$ reconstruction at the depths of the halocline remains large. The estimation would be improved with the FOAGRNN model trained within the equatorial west Pacific instead of the whole tropical Pacific Ocean. 


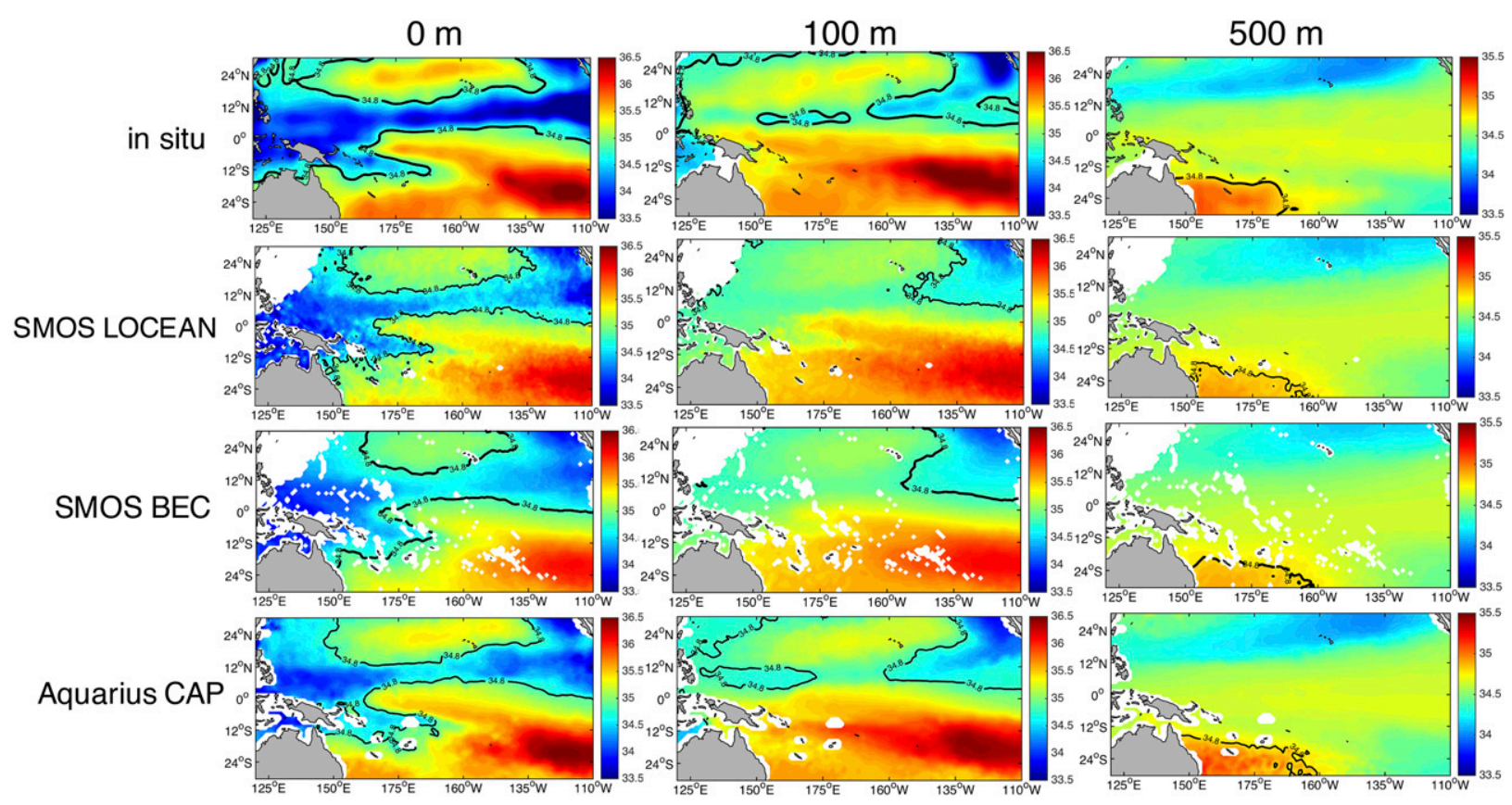

FIG. 14. Comparison of the estimated salinity fields and in situ data at depths of (left) 0, (middle) 100, and (right) $500 \mathrm{~m}$ in January 2014. The SSS data used are (from top to bottom) monthly in situ, SMOS LOCEAN, SMOS BEC, and Aquarius CAP data. This figure illustrates the differences in salinity fields estimated by the different sources of SSS data.

In addition, as a statistical approach, the FOAGRNN method is highly dependent on historical training data. It predicts salinity within the "ranges" of training data, and this may underestimate and miss the signal of some large anomaly events (Fig. 6e).

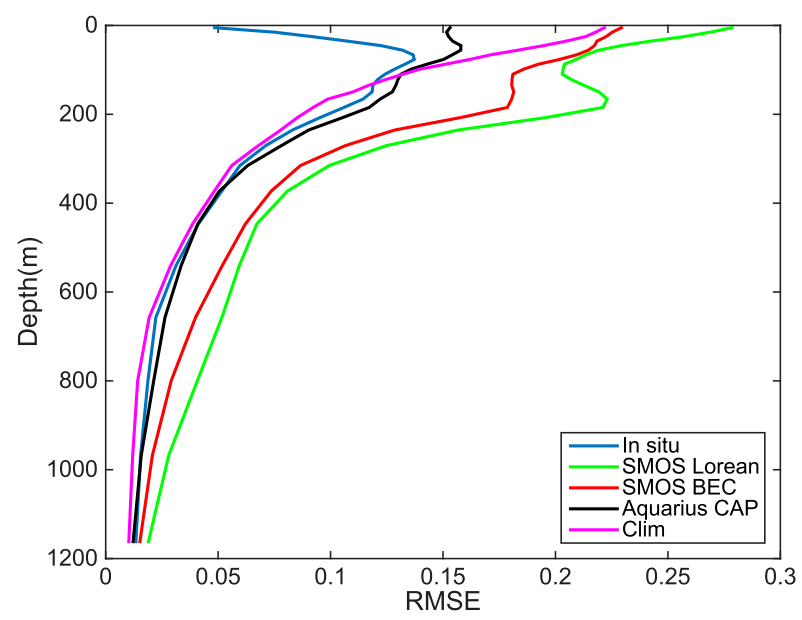

FIG. 15. The RMSE of models with different SSS inputs as a function of depth in 2014. The SSS input data are from the EN.4.1.1 objective analyses (the blue profile), SMOS LOCEAN (the green profile), SMOS BEC (the red profile), and Aquarius CAP data (the black profile). The pink Clim profile refers to the RMSE of the monthly gridded WOA salinity data with the EN.4.1.1 objective analyses in 2014.
The other error source is induced from inaccurate SSS values. First, the satellite SSS data still have various types of errors from the instrument's observations, brightness temperature $\mathrm{Tb}$ reconstruction, and salinity retrieval algorithm, especially at high latitudes. Second, the SSS input data in the training process and testing process are different, which are from the uppermost layer of in situ salinity profiles (about

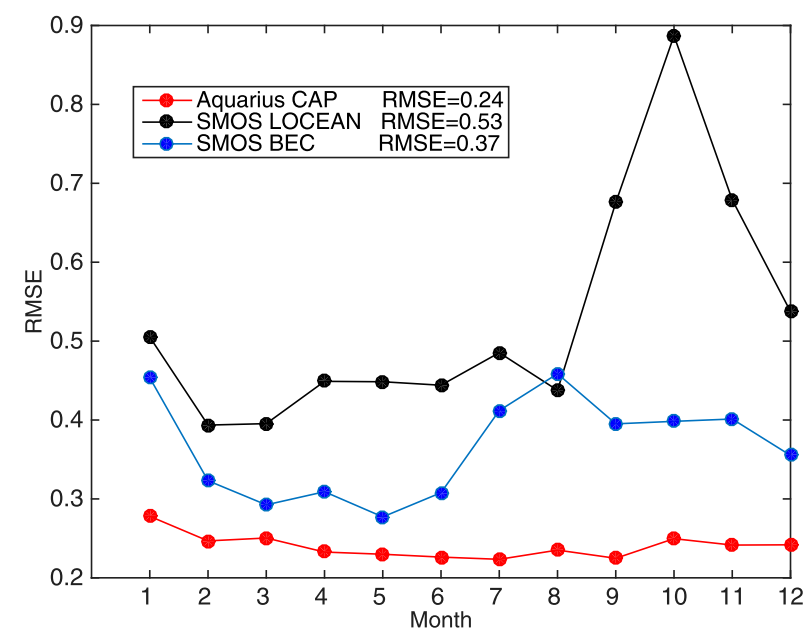

FIG. 16. The RMSE of satellite SSS products compared with the in situ data in the tropical Pacific Ocean from January 2013 to December 2014. 


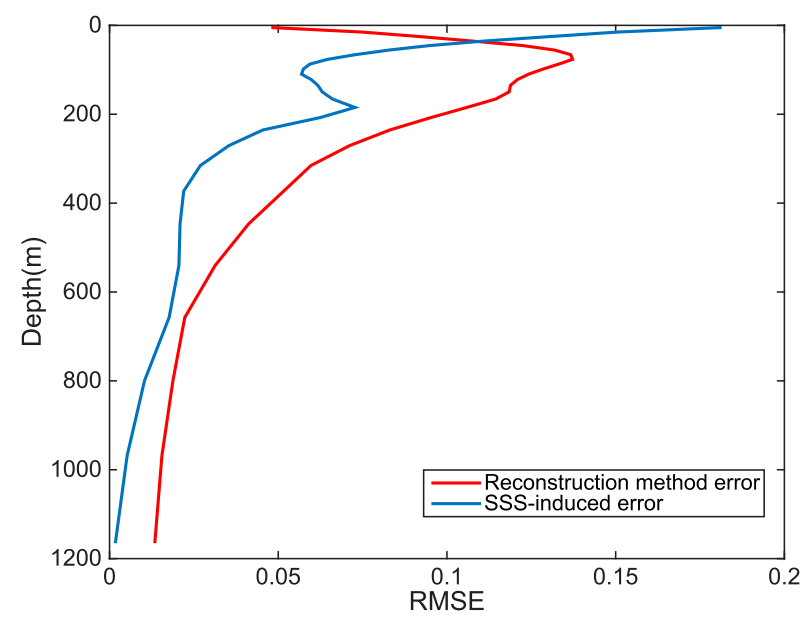

FIG. 17. Profiles of two errors (red line: reconstruction method error; blue line: SSS-induced error).

5-10 m) and satellite SSS data (1-2 cm of ocean), respectively. The difference between in situ salinity observations and satellite SSS data is large in the regions with significant near-surface stratification. Further investigations should be done to describe the characteristic of the relationship between Argo SSS and satellite SSS.

The results in this work have illustrated the better performance of the FOAGRNN method at the halocline with great vertical gradient compared with linear regressions. The advantage of nonlinear regressions may be explained by the fact that the nonlinear model has five explicit predictors (SST, SLA, SSS, LON, and LAT), while the linear model has only two explicit predictors (SLA and SSS). In particular, our results indicate that the greatest improvement, especially below $100 \mathrm{~m}$ in depth, is obtained when geographical information is explicitly included as predictors, with latitude information being the primary factor to improve the accuracy of the reconstruction effect in the Pacific. It is noted that the ability of sea surface information to retrieve subsurface salinity and the depth to which the surface information reduces the retrieval error will change with position. In addition, the results show that the estimated 3D salinity fields perform well compared to the in situ salinity fields in reflecting large-scale salinity characteristics and that the errors of the satellite SSS data limited the performance of the estimated salinity fields.

Finally, these results indicate that more accurate subsurface salinity profiles can be obtained using this proposed method with the use of future accurate satellite SSS data, which is useful for better analyzing the salinity variability and better initial conditions for reliable forecasting.
Acknowledgments. This work was supported by the National Key R\&D Program of China (2018YFC1406202) and the National Natural Science Foundation of China Youth Science Fund Project (41706021). The EN.4.1.1 dataset used in this study is provided by the Met Office Hadley Centre and can be accessed online (https://www. metoffice.gov.uk/hadobs/en4/download-en4-1-1.html). SMOS LOCEAN data were provided by the Centre Aval de Traitement des Données SMOS (CATDS), operated for the Centre National d'Etudes Spatiales (CNES; France) by IFREMER (Brest, France) (www. catds.fr/Products/Available-products-from-CPDC). SMOS BEC data are produced by the Barcelona Expert Center (BEC) in Spain (http://cp34-bec.cmima.csic.es). Aquarius data are provided by NASA's Physical Oceanography Distributed Active Archive Center (PO.DAAC) (ftp:// podaac-ftp.jpl.nasa.gov/allData/aquarius/). The altimeter products (SLA data) were produced by SSALTO/ DUACS and distributed by AVISO with support from CNES (http://www.aviso.oceanobs.com/duacs/). We wish to thank the editor of the Journal of Atmospheric and Oceanic Technology and three anonymous reviewers for their valuable suggestions and comments.

\section{REFERENCES}

Agarwal, N., R. Sharma, S. Basu, and V. K. Agarwal, 2007: Derivation of salinity profiles in the Indian Ocean from satellite surface observations. IEEE Geosci. Remote Sens. Lett., 4, 322-325, https://doi.org/10.1109/LGRS.2007.894163.

Ballabrera-Poy, J., R. Murtugudde, and A. J. Busalacchi, 2002: On the potential impact of sea surface salinity observations on ENSO predictions. J. Geophys. Res., 107, 8007, https://doi.org/ 10.1029/2001JC000834.

— B. Bourre, E. Garcia-Ladona, A. Turiel, and J. Font, 2009: Linear and non-linear $T-S$ models for the eastern North Atlantic from Argo data: Role of surface salinity observations. Deep-Sea Res. I, 56, 1605-1614, https://doi.org/10.1016/ j.dsr.2009.05.017.

Carnes, M. R., W. J. Teague, and J. L. Mitchell, 1994: Inference of subsurface thermohaline structure from fields measurable by satellite. J. Atmos. Oceanic Technol., 11, 551-566, https:// doi.org/10.1175/1520-0426(1994)011<0551:IOSTSF>2.0.CO;2.

Chen, J., X. You, Y. Xiao, R. Zhang, G. Wang, and S. Bao, 2017: A performance evaluation of remotely sensed sea surface salinity products in combination with other surface measurements in reconstructing three-dimensional salinity fields. Acta Oceanol. Sin., 36, 15-31, https://doi.org/10.1007/s13131-017-1079-y.

de Boyer Montégut, C., J. Mignot, A. Lazar, and S. Cravatte, 2007: Control of salinity on the mixed layer depth in the world ocean: 1. General description. J. Geophys. Res., 112, C06011, https://doi.org/10.1029/2006JC003953.

Fox, D. N., C. N. Barron, M. R. Carnes, M. Booda, G. Peggion, and J. Van Gurley, 2002a: The modular ocean data assimilation system. Oceanography, 15 (1), 22-28, https://doi.org/10.5670/ oceanog.2002.33.

, W. J. Teague, C. N. Barron, M. R. Carnes, and C. M. Lee, 2002b: The Modular Ocean Data Assimilation System 
(MODAS). J. Atmos. Oceanic Technol., 19, 240-252, https:// doi.org/10.1175/1520-0426(2002)019<0240:TMODAS > 2.0.CO;2.

Gao, S., J. Tian, F. Wang, and Y. Bai, 2015: The study of GRNN for wind speed forecasting based on Markov Chain. 2015 International Conference on Modeling, Simulation and Applied Mathematics, Advances in Intelligent Systems Research, Vol. 122, Atlantis Press, 285-288, https://doi.org/10.2991/msam-15.2015.66.

Good, S. A., M. J. Martin, and N. A. Rayner, 2013: EN4: Quality controlled ocean temperature and salinity profiles and monthly objective analyses with uncertainty estimates. J. Geophys. Res. Oceans, 118, 6704-6716, https://doi.org/10.1002/2013JC009067.

Gueye, M. B., A. Niang, S. Arnault, S. Thiria, and M. Crépon, 2014: Neural approach to inverting complex system: Application to ocean salinity profile estimation from surface parameters. Comput. Geosci., 72, 201-209, https://doi.org/10.1016/ j.cageo.2014.07.012.

Guinehut, S., A. L. Dhomps, G. Larnicol, and P. Y. Le Traon, 2012: High resolution 3-D temperature and salinity fields derived from in situ and satellite observations. Ocean Sci., 8, 845-857, https://doi.org/10.5194/os-8-845-2012.

Hansen, D. V., and W. C. Thacker, 1999: Estimation of salinity profiles in the upper ocean. J. Geophys. Res., 104, 7921, https:// doi.org/10.1029/1999JC900015.

Helber, R. W., J. G. Richman, and C. N. Barron, 2010: The influence of temperature and salinity variability on the upper ocean density and mixed layer. Ocean Sci. Discuss., 7, 1469-1495, https://doi.org/10.5194/osd-7-1469-2010.

Kerr, Y. H., and Coauthors, 2010: The SMOS Mission: New tool for monitoring key elements of the global water cycle. Proc. IEEE, 98, 666-687, https://doi.org/10.1109/JPROC.2010.2043032.

Krasnopolsky, V. M., 2007: Neural network emulations for complex multidimensional geophysical mappings: Applications of neural network techniques to atmospheric and oceanic satellite retrievals and numerical modeling. Rev. Geophys., 45, RG3009, https://doi.org/10.1029/2006RG000200.

, 2013: The Application of Neural Networks in the Earth System Sciences: Neural Networks Emulations for Complex Multidimensional Mappings. Atmospheric and Oceanographic Sciences Library, Vol. 46, Springer, 189 pp., https://doi.org/ 10.1007/978-94-007-6073-8.

— C. J. Lozano, D. Spindler, I. Rivin, and D. B. Rao, 2006: Using neural network to enhance assimilating sea surface height data into an ocean model. 2006 IEEE International Joint Conference on Neural Network Proceedings, IEEE, 4299-4301, https://doi.org/ 10.1109/IJCNN.2006.247004.

Le Vine, D. M., G. S. Lagerloef, and S. Torrusio, 2010: Aquarius and remote sensing of sea surface salinity from space. Proc. IEEE, 98, 688-703, https://doi.org/10.1109/JPROC.2010.2040550.

Li, H., S. Guo, C. Li, and J. Sun, 2013: A hybrid annual power load forecasting model based on generalized regression neural network with fruit fly optimization algorithm. Knowl. Based Syst., 37, 378-387, https://doi.org/10.1016/j.knosys.2012.08.015.

Lin, S.-M., 2013: Analysis of service satisfaction in web auction logistics service using a combination of Fruit fly optimization algorithm and general regression neural network. Neural Comput. Appl., 22, 783-791, https://doi.org/10.1007/s00521-011-0769-1.

Lixi, Z., S. Pengbo, J. Fang, Q. Hengqing, R. Shumei, L. Yunkai, and Z. Yu, 2014: Using monitoring data of surface soil to predict whole crop-root zone soil water content with PSOLSSVM, GRNN and WNN. Earth Sci. Inf., 7, 59-68, https:// doi.org/10.1007/s12145-013-0130-6.

Maes, C., D. Behringer, R. W. Reynolds, and M. Ji, 2000: Retrospective analysis of the salinity variability in the western tropical
Pacific Ocean using an indirect minimization approach. J. Atmos. Oceanic Technol., 17, 512-524, https://doi.org/ 10.1175/1520-0426(2000)017<0512:RAOTSV>2.0.CO;2.

Nardelli, B. B., and R. Santoleri, 2004: Reconstructing synthetic profiles from surface data. J. Atmos. Ocean. Technol., 21, 693-703, https://doi.org/10.1175/1520-0426(2004)021<0693: RSPFSD $>2.0 . \mathrm{CO} ; 2$.

, 2005: Methods for the reconstruction of vertical profiles from surface data: Multivariate analyses, residual GEM, and variable temporal signals in the North Pacific Ocean. J. Atmos. Oceanic Technol., 22, 1762-1781, https://doi.org/10.1175/ JTECH1792.1.

Pan, W. T., 2012: A new fruit fly optimization algorithm: Taking the financial distress model as an example. Knowl.-Based Syst., 26, 69-74, https://doi.org/10.1016/j.knosys.2011.07.001.

Qin, S., Q. Zhang, and B. Yin, 2015: Seasonal variability in the thermohaline structure of the Western Pacific Warm Pool. Acta Oceanol. Sin., 34, 44-53, https://doi.org/10.1007/s13131015-0696-6.

Qu, T., and J. Y. Yu, 2014: ENSO indices from sea surface salinity observed by Aquarius and Argo. J. Oceanogr., 70, 367-375, https://doi.org/10.1007/s10872-014-0238-4.

Rao, R. R., and R. Sivakumar, 2003: Seasonal variability of sea surface salinity and salt budget of the mixed layer of the north Indian Ocean. J. Geophys. Res., 108, 3009, htts://doi.org/ 10.1029/2001JC000907.

Singh, A., and T. Delcroix, 2011: Estimating the effects of ENSO upon the observed freshening trends of the western tropical Pacific Ocean. Geophys. Res. Lett., 38, L21607, https://doi.org/ 10.1029/2011GL049636.

Specht, D. F., 1991: A general regression neural network. IEEE Trans. Neural Networks, 2, 568-576, https://doi.org/10.1109/ 72.97934 .

Umbert, M., N. Hoareau, A. Turiel, and J. Ballabrera-Poy, 2014: New blending algorithm to synergize ocean variables: The case of SMOS sea surface salinity maps. Remote Sens. Environ., 146, 172-187, https://doi.org/10.1016/j.rse.2013.09.018.

Verma, P., P. Singh, and R. D. S. Yadava, 2015: A fuzzy-GRNN classifier for pattern recognition. 2015 2nd International Conference on Signal Processing and Integrated Networks (SPIN 2015), IEEE, 659-661, https://doi.org/10.1109/SPIN.2015.7095166.

Wang, H., and R. Zhang, 2012: Freshwater flux product reconstruction based on Argo data and mixed layer model. Acta Phys. Sin., 61, 039202, https://doi.org/10.7498/aps.61.039202.

—, G. Wang, D. Chen, and R. Zhang, 2012: Reconstruction of three-dimensional Pacific temperature with Argo and satellite observations. Atmos.-Ocean, 50, 116-128, https://doi.org/ 10.1080/07055900.2012.742421.

Wu, X., X. H. Yan, Y. H. Jo, and W. T. Liu, 2012: Estimation of subsurface temperature anomaly in the North Atlantic using a self-organizing map neural network. J. Atmos. Oceanic Technol., 29, 1675-1688, https://doi.org/10.1175/JTECH-D-12-00013.1.

Yueh, S. H., and J. Chaubell, 2012: Sea surface salinity and wind retrieval using combined passive and active L-band microwave observations. IEEE Trans. Geosci. Remote Sens., 50, 1022-1032, https://doi.org/10.1109/TGRS.2011.2165075.

Zhou, K., D. Yu, Z. Lin, B. Cao, Z. Wang, and S. Guo, 2016: Anode effect prediction of aluminum electrolysis using GRNN. Proceedings of the 2015 Chinese Automation Congress (CAC 2015), IEEE, 853-858, https://doi.org/10.1109/CAC.2015.7382617.

Zhu, J., B. Huang, R.-H. Zhang, Z.-Z. Hu, A. Kumar, M. A. Balmaseda, L. Marx, and J. L. Kinter III, 2014: Salinity anomaly as a trigger for ENSO events. Sci. Rep., 4, 6821, https://doi.org/10.1038/srep06821. 